\title{
Why Enjoying Your Fun Matters: The Role of Participation in Fun Activities, Positive Affect, and Citizenship Pressure on Knowledge Management Behaviors
}

\author{
Jessica Good \\ York University \\ jlrgood@yorku.ca
}

\author{
Michael Halinski \\ Ryerson University \\ $\underline{\text { michael.halinski@ryerson.ca }}$
}

\author{
Janet A. Boekhorst \\ University of Waterloo \\ janet.boekhorst@uwaterloo.ca
}

\begin{abstract}
Drawing from social exchange theory, this research develops a mediated-moderation model that examines the direct and indirect effects of participation in fun activities on three knowledge management behaviors (i.e., knowledge sharing, knowledge hiding, knowledge manipulating) and investigates the mediating role of positive affect and the moderating role of citizenship pressure on these relationships. A three-wave, twosource sample $(n=163)$ of employees belonging to a high-tech start-up in Canada is used to test this model. Results highlight the importance of positive affect by showing the effects of participation in fun activities on knowledge management behaviors is dependent on whether or not participation in fun activities leads to positive affect. Data also shows citizenship pressure moderates the direct relationship between participation in fun activities and knowledge manipulating, as well as the indirect relationship between participation in fun activities and both knowledge sharing and hiding. These results highlight the theoretical and practical importance of both positive affect and citizenship pressure in understanding the dynamic relationship between workplace fun and knowledge management.
\end{abstract}

\section{Introduction}

The shift towards a knowledge-based economy has recently underscored some significant challenges surrounding positive knowledge management behaviors among employees $[1,2]$. It is essential for us to understand how knowledge is managed between employees [3] because positive knowledge management behaviors have a positive impact on an organization's competitive advantage $[1,2,4]$.

One way in which organizations have sought to facilitate more positive knowledge management behaviors is by creating 'fun' opportunities that enable employees to connect with others outside of their immediate group [1,2,]. Workplace fun refers to “.... any social, interpersonal, or task activities at work of a playful or humorous nature which provide an individual with amusement, enjoyment, or pleasure" [5 p. 5]. Specifically, fun activities provide opportunities for social interactions with others beyond an employee's immediate team [5]. Indeed, these social interactions are essential to promote knowledge exchange [6]. Despite this rationale and the fact that a plethora of organizations are working towards injecting more fun activities into the workplace [5, 7, 8, 9], research has not yet empirically examined how the interpersonal interactions that are inherent in fun activities may facilitate positive knowledge management behaviors (KMBs).

KMBs are behaviors employees perform when identifying and leveraging their knowledge within an organization [10]. While KMBs can lead to positive organizational outcomes including knowledge creation [10], we do not know what motivates individuals to engage in these behaviors $[11,12]$. We extend the literature by looking at three distinct KMBs have been identified: knowledge sharing, hiding, and manipulating [11]. When employees are faced with an opportunity to exchange knowledge, they face a motivational tension whether to share their knowledge for collective interests or to hide / manipulate their knowledge for personal interests [12].While workplace fun is generally positioned to foster collective interests [7], there is a growing collection of empirical studies that show employees may not enjoy participating in fun activities and/or participate for personally strategic reasons [e.g., $13,14,15,16,17,18]$.

We draw from social exchange theory $[19,20,21]$ to address these mixed findings and extend the literature in two ways. First, this research explores the mediating role of positive affect in the relationship between participation in fun activities and KMBs. Using a social exchange lens, we posit that employees give to the organization by participating in employer-sponsored fun activities and, in return, these activities provide employees with opportunities to strategically use their knowledge [12]. We theorize that, when participation in fun activities leads to positive affect, employees will be more likely to perform KMBs that are consistent with 
collective interests (i.e., increased sharing, decreased hiding, decreased manipulating). This study extends the workplace fun literature by identifying a new outcome of workplace fun and confirms the importance of employees enjoying the fun activities they participate in [7].

Second, we introduce citizenship pressure (CP) as a novel contingency for the effects of participation in fun activities on KMBs. CP reflects the degree to which employees feel they are obligated to help their peers [22, 23]. Specifically, we theorize that, when CP is high, participation in fun activities will contribute to KMBs in a manner that is consistent with collective interests. By investigating how $\mathrm{CP}$ moderates this relationship, we extend the literature and address Michel et al.'s [7] call for additional research that looks at the contextual factors that impact workplace fun. It is important for us to understand the impact of $\mathrm{CP}$ on $\mathrm{KMB}$ because the literature has shown that that $\mathrm{CP}$ can have positive and negative impacts on employees [24, 25], which to our knowledge have not been explored in the knowledge management domain.

\section{Theoretical Framework}

As theorization of workplace fun has been traditionally limited to affective events theory [26] and broaden-and-build theory [27], researchers have recently called for future research to use alternative theoretical frameworks to broaden our understanding of this fun phenomenon [7]. This study addresses this call by examining the effects of participation in fun activities from a social exchange theory (SET) perspective. SET has been used to describe how organizational mechanisms (e.g., promotions, compensation) can positively impact KMBs [2] and, as such, fits well with our study that explores how one organizational mechanism (i.e. employer-sponsored workplace fun activities) may shape KMBs. In the section to follow, we first describe SET and then use it to ground our study of participation in workplace fun and KMB.

According to Blau [20], any exchange relationship can be explained by either social or economic principles. He describes social exchanges as "...voluntary actions of individuals that are motivated by the returns they are expected to bring and typically do in fact bring from others" [20 p. 91]. In summary, when social exchanges occur, it is anticipated that the transfer of the resources that happen in these exchanges will provide some benefit to the individual receiving said exchange. Blau [20] argues that when an individual does something for another actor, both of them, in turn, expect that in the future, this "favour" will, at some point be reciprocated. Thus, the scope of this theory is limited to social exchanges that are dependent upon the rewarding actions of another, i.e., it is a two-sided, mutually contingent and rewarding process of exchanges [28]. What is fundamental to this theory is that the behaviour must enable one to achieve a goal through one's social interactions with others [29].

In line with SET [20], we develop a theoretical model (figure 1) that explains the relationship between participation in workplace fun and knowledge management behavior. The social exchange process begins when an organizational actor treats a target in a positive (or negative) fashion and, in response, the target reciprocates by replying in kind [21], In the context of workplace fun, we theorize that employees give to the organization by participating in employer-sponsored fun activities and, in return, these activities provide employees with opportunities to strategically develop and use their knowledge [12].

Figure 1: A moderated-mediation model of participation in fun activities, positive affect, and knowledge management behaviors

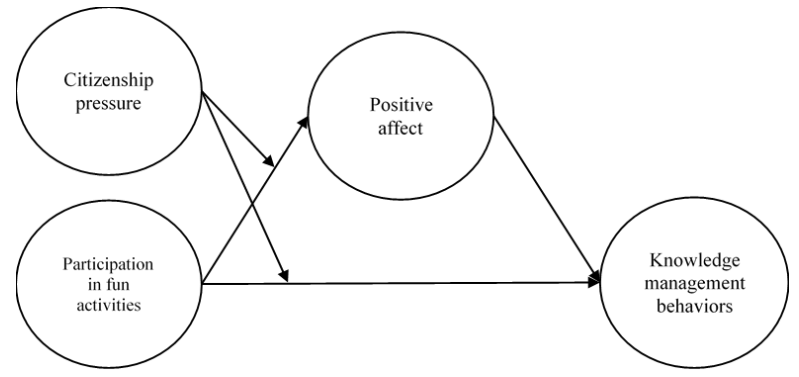

Rhee and Choi [11] find employees may use their knowledge by engaging three main knowledge management behaviors (KMB): knowledge sharing refers to the provision of task information [2]; knowledge hiding is the intentional attempt to withhold or conceal knowledge [30], and, knowledge manipulating is the intentional exaggeration of the value or content of one's knowledge [11]. Inline with SET, we posit that the KMBs that employees choose to employ will be dependent on the exchange relationship they have with the organization. First, we theorize that employees give to their organization by participating in fun activities (i.e. an initiating action) [12], and in doing so, employees are rewarded by the opportunity to strategically use their knowledge (i.e. a reciprocal response). Secondly, we posit that how employees experience workplace fun activities impacts the KMBs they choose to employ. More specifically, when employees experience positive affect, they are more likely to reciprocate to the organization by choosing positive KMBs (i.e., increased sharing, decreased hiding, decreased manipulating). 
The model also hypothesizes the moderating impact of citizenship pressure on two relationships. We suggest that citizenship pressure moderates the direct and indirect relationship between participation in fun activities and KMBs. When employees have high citizenship pressure (i.e. employees feel obligated to engage in helping behaviors in order to obtain the subsequent rewards), it will strengthen the exchange relationship, and employees will feel a greater desire to give back to the organization by using positive KMBs.

In the section to follow, we will further explain our propositions that describe the relationship between participation in fun activities and KMB.

\section{Hypothesis Development}

When employees participate in fun activities, they are provided with the opportunity to transfer knowledge [30]. The workplace fun literature suggests that, when employees have the opportunity to engage in fun activities with their peers, it enables them to share ideas and knowledge freely [31, 32] Participating in fun activities encourages social interaction [9] and allows employees to interact with employees who are not in their immediate social network at work [7]. As a result, participants are likely to be in situations where they: (1) have knowledge to share; (2) have confidential knowledge that they wish to hide [33]; and, (3) are interacting with people who are unable to validate whether the shared knowledge is accurate, thus reducing evaluation apprehension [34]. As such, we posit that participation in fun activities increases employee's ability to engage in all KMBs. This leads us to the following hypotheses.

\section{Hypothesis 1: Participation in fun activities positively relates to (a) knowledge sharing, (b) knowledge hiding, and (c) knowledge manipulating.}

In a recent review of social exchange theory, Cropanzano et al. [21] contend that reciprocity could be mediated by a positive affective state: "hedonically positive initiating actions could engender positive affect, which in turn could encourage hedonically positive reciprocating responses" (p. 24). Consistent with this logic, participation in fun activities may promote positive emotions [5], which subsequently promote positive KMBs [11]. In such situations, the positive affect experienced from participating in the fun activities would be, according to SET, the positive reward the individual receives from the social exchange and, thus, would be less likely to seek out a positive reward in the form of KMBs.
Accordingly, we hypothesize positive affect mediates the relationship between participation in fun activities and KMBs in the following manner. First, individuals participating in fun activities may experience positive affect from their participation in the fun activity. Second, individuals experiencing this positive affect are, in turn, more likely to engage in positive KMBs to reciprocate to the organization in a positive manner (i.e., increased sharing, decreased hiding, decreased manipulating). This hypothesis is supported by research that has found that when individuals experience positive affect it increases their desire to share knowledge [18, 35].

Hypothesis 2: Positive affect (a) positively
mediates the relationship between participation
in fun activities and knowledge sharing, (b)
negatively mediates the relationship between
participation in fun activities and knowledge
hiding, and (c) negatively mediates the
relationship between participation in fun
activities and knowledge manipulating.

Drawing on the organizational citizenship pressure (OCB) literature, citizenship pressure "... is experienced by employees when the organization or the work environment formally or informally rewards helping behaviors, such as giving more approval, more positive evaluations, or faster promotions to employees who help their coworkers more" [22. p. 4]. When employees experience high citizenship pressure (CP), they feel an obligation to help their co-workers because they "must" and will be rewarded by the organization for doing so $[34,35]$. Conversely, when citizenship pressure is low, employees feel less pressure to go above and beyond to help their co-workers [22, 23].

In the context of workplace fun, we expect citizenship pressure to moderate the relationship between participation in fun activities and KMBs. In particular, we expect citizenship pressure to encourage employees participating in fun activities to share their knowledge with their colleagues, as anticipation for organizational rewards will lead to positive helping behaviors [23]. This logic is consistent with studies in the KMB literature that show rewards such as promotions and monetary incentives lead to positive KMB (e.g. knowledge sharing) [2]. At the same time, citizenship pressure will also discourage employees participating in fun activities to either hide or manipulate their knowledge, as they will anticipate in doing so they will not be rewarded, and in fact, they may even be punished for this behavior [24]. This leads us to the below hypotheses. 
Hypothesis 3: Citizenship pressure (a) positively moderates the relationship between participation in fun activities and knowledge sharing, (b) negatively moderates the relationship between participation in fun activities and knowledge hiding, and (c) negatively moderates the relationship between participation in fun activities and knowledge manipulating.

As argued above, participation in fun activities may promote positive emotions [5], including positive affect. Using SET terminology [21], a hedonically positive initiating action (i.e. participation in fun activities) may promote positive affect. The extent to which someone feels positive affect from participating in fun activities is, however, likely to be moderated by the extent there is pressure in the work environment to go above and beyond their regular job duties. In line with SET, employees experiencing citizenship pressure are more likely to believe that they will experience rewards for positive helping behaviours [23]. As participation in fun activities has been viewed as positive organizational behaviors [7], we hypothesize that employees experiencing citizenship pressure will receive more rewards in the form of positive affect from participating in fun activities.

\section{Hypothesis 4: Citizenship pressure positively moderates the relationship between participation in fun activities and positive affect.}

To further understand the impact of citizenship pressure on our theoretical model, we hypothesize a conditional indirect effect. Hypothesis 2 postulates that participation in fun activities provides an indirect effect on KMBs through positive affect (due to characterizing participation in fun activities as a hedonically positive initiating action). Hypothesis 4 then postulates that citizenship pressure amplifies the relation between participation in fun activities and positive affect (due to employees anticipating greater rewards for participating in fun activities). Together, these hypotheses suggest that the indirect effect of participation in fun activities on KMBs, through positive affect, will be contingent on citizenship pressure. Accordingly, we posit the following overall relation reflecting the predicted conditional indirect effects of participation in fun activities and citizenship pressure, through positive affect, on KMBs (Hypothesis 5).

Hypothesis 5: Citizenship pressure moderates the indirect effect of participation in fun activities on knowledge management behaviors through positive affect. Specifically, we predict that, when citizenship pressure is high, there will be a (a) positive indirect effect of participation in fun activities on knowledge sharing, (b) negative indirect effect of participation in fun activities on knowledge hiding, and (c) negative indirect effect of participation in fun activities on knowledge manipulating.

\section{Methods}

\subsection{Sample}

This study draws on a three-wave, two-source survey data to test these hypotheses to avoid common method bias [36, 37]. Voluntary participation from employees working in a high-growth, high-tech start-up located in Canada was solicited from the first author. We selected employees from this organization, as this organization is typical of a small to medium sized tech-start up in Canada, specializing in both software and hardware. Specifically, knowledge sharing is particularly important in this organization [38], and employees in this organization commonly engage in workplace fun activities [7, 8], such as trips, sporting events, celebration of achievements, and fun team building activities (i.e., paintball, trivia)

The three waves of data were collected by one-week intervals. A three-wave study design that temporally separated the predictor, moderator/mediator and outcome variable was used to reduce common method bias [37]. A two-week time frame was assessed by the organization as suitable based upon the organization events occurring at the time. Employee identification numbers and an organizational chart were used to link employees' surveys over time and to their manager's surveys. All employees $(n=389)$ received an email invitation to participate in each survey. Two hundred fifteen employees completed the first survey (response rate of 55\%), two hundred nineteen employees completed the second survey (response rate of 56\%), and two hundred thirteen employees completed the third survey (response rate of 55\%). Together, one hundred sixty-three employees completed all three surveys (overall response rate of $42 \%$ ).

The majority of the sample was male $(71 \%)$ and well-educated (76\% hold a university degree or higher). Approximately two thirds of the sample $(68 \%)$ were between the ages of 18 and 35 years old. While the average tenure in the organization was just over a year (1.4 years), the average number of years in the field was 11.9. This sample consists of 39 (24\%) managers who manage teams ranging from 2 and 19 team members.

\subsection{Measures}


Participation in fun activities (employee-rated, Time 1) was operationalized using Tews et al. [9] 5-item scale. We adapted items slightly for the current context. Individuals responded to items such as "Public celebrations of work achievements (e.g., public recognition for outstanding results)" using a 5-point Likert scale ranging from 1 (never) to 5 (all the time).

Positive affect (employee-rated, Time 2) was measured using Watson, Clark, and Tellegen's [39]item scale. Respondents were asked to think about how they normally feel and to what extent they generally feel, for example, attentive. Individuals responded to these items using a 5 -point Likert scale $(1=$ never; $5=$ always).

Knowledge management behaviors (employee-rated, Time 3) were measured using Rhee and Choi's [11] 12item scale. These items were introduced by first defining the term knowledge: "knowledge refers to certain facts, experience, information, and technology that can be earned through education, learning, mastery, and experience". The respondents were then asked to respond to line items associated with each of the three types of knowledge management behaviors - sharing (e.g. "I explain everything very thoroughly"), hiding (e.g. "I pretend that I do not know the information"), and manipulating (e.g. "I pad my knowledge to make it greater than it actually is"). Each type of knowledge management behavior was assessed with four items using a 5-point Likert scale ranging from 1 (strongly disagree) to 5 (strongly agree).

Citizenship pressure (manager-rated, Time 1) was operationalized using four items from Bolino, Hsiung, $\&$ Harvey [40]. A senior manager from the organization asked us to remove four items from the original measure that she felt was too harsh (e.g. "In this organization, the people who are seen as 'team players' are the ones who do significantly more than what is technically required of them"). We elected to have managers rate citizenship pressure because managers are better positioned to view the forces acting on their teams [41]. The stem read: "Please rate the extent to which you agree or disagree with the following statements about work pressures". Respondents evaluated items (e.g. "There is a lot of pressure to take on additional responsibilities and volunteer for extra assignments in this organization") using a 5-point Likert scale ( $1=$ strongly disagree; $5=$ strongly agree).

Three control variables were included in the first survey. Gender, organizational tenure, and years in field were included in the analysis as control variables, given that these demographic variables have been related to fun [42]. Gender was coded as Male $=1$.

\subsection{Procedure}

The validity of the study measures was first assessed using confirmatory factor analysis (CFA) on the hypothesized measurement model, which included six latent variables (i.e., participation in fun activities, positive affect, knowledge sharing, knowledge hiding, knowledge manipulating, citizenship pressure). All paths were freely estimated and error variances were constrained to one. We assessed model fit using the following parameters: (a) chi-square goodness of fit to degrees of freedom ratio $\left(\chi^{2} / d f\right)$ should be less than 2 [44], (b) Tucker-Lewis index (TLI) should be at least .90 [45], (c) the comparative fit index (CFI) should be .90 or greater [45], d) root-mean-square error of approximation (RMSEA) should be less than .07 [46], and (e) standardized root mean square residual (SRMR) should be less than .08 [46]. The mediation hypotheses were tested using nested structural equation models [47], while the moderation hypotheses were tested using latent interaction SEM techniques [48]. In both cases, bootstrapping procedures were used to test the significance of the hypothesized direct, indirect, and moderating paths [47].

\section{Results}

Table 1 summarizes the means, standard deviations, and correlations between study variables. No correlations are above .4. The measurement model reveals adequate fit $\left(\chi^{2}=217.30 ; d f=164 ; \chi^{2} / d f=1.32\right.$; $\mathrm{CFI}=.95 ; \mathrm{TLI}=.93 ;$ SRMR $=.056$; RMSEA $=.04)$. For purposes of comparison, the hypothesized measurement model was compared to a one-factor model, in which all of the hypothesized variables were set to load on a single underlying factor $\left(\chi^{2} / d f=1.33\right.$; $\mathrm{CFI}=.94 ; \mathrm{TLI}=.93 ; \mathrm{SRMR}=.056 ;$ RMSEA $=.04)$, and a two-factor model, in which the Time 3 variables were set to load on one factor and all other variables were set to load on another factor $\left(\chi^{2} / d f=1.28 ; \mathrm{CFI}=\right.$ $.95 ;$ TLI $=.93 ;$ SRMR $=.055$; RMSEA = .04). Neither comparative model demonstrated an improvement to fit indices or a significant change in chi-square test in comparison to the hypothesized measurement model.

\subsection{Direct Effects}

Structural equation modelling analysis revealed adequate fit $\left(\chi^{2}=237.802 ; d f=167 ; \chi^{2} / d f=1.424 ; \mathrm{CFI}\right.$ $=.927$; TLI $=.908 ;$ SRMR $=.076$; RMSEA $=.051)$. Figure 2 summarizes the structural equation modelling analysis. Results provide partial support for Hypothesis 1 , which posited participation in fun activities directly, positively relates to each of the three knowledge management behaviors. Results should participation in 
fun activities directly, positively relates to knowledge sharing $(\beta=.156, p<.05)$ and knowledge manipulating $(\beta=.148, p=.062)$ but not knowledge hiding $(\beta=-.041$, n.s.).

Table 1: Means, Standard Deviations, and Correlations $(\mathrm{n}=163)$

\begin{tabular}{|c|c|c|c|c|c|c|c|c|c|c|c|}
\hline & Mean & $\begin{array}{l}\text { Standard } \\
\text { Deviation }\end{array}$ & 1 & 2 & 3 & 4 & 5 & 6 & 7 & 8 & 9 \\
\hline 1. Gender & .29 & .45 & & & & & & & & & \\
\hline $\begin{array}{l}\text { 2. Years in } \\
\text { organization }\end{array}$ & 1.44 & 1.17 & -.11 & & & & & & & & \\
\hline 3. Years in field & 11.65 & 8.81 & $-.18^{*}$ & .11 & & & & & & & \\
\hline $\begin{array}{l}\text { 4. Participation in } \\
\text { fun activities }\end{array}$ & 2.75 & .83 & .06 & .04 & -.01 & $(.75)$ & & & & & \\
\hline 5. Positive affect & 3.60 & .65 & .10 & -.10 & .05 & $.38^{* * * *}$ & $(.87)$ & & & & \\
\hline $\begin{array}{l}\text { 6. Knowledge } \\
\text { sharing }\end{array}$ & 4.15 & .46 & .02 & .12 & $.16^{*}$ & $.22^{* *}$ & $.36^{* * *}$ & $(.92)$ & & & \\
\hline $\begin{array}{l}\text { 7. Knowledge } \\
\text { hiding }\end{array}$ & 1.22 & .38 & $-.20^{* *}$ & -.02 & -.01 & -.08 & $-.20^{*}$ & $-.24^{* * * *}$ & $(.78)$ & & \\
\hline $\begin{array}{l}\text { 8. Knowledge } \\
\text { manipulating }\end{array}$ & 1.97 & .65 & .03 & $-.16^{*}$ & $-.27^{* * * *}$ & .11 & -.08 & $-.17^{*}$ & $.36^{* * * *}$ & $(.78)$ & \\
\hline $\begin{array}{l}\text { 9. Citizenship } \\
\text { pressure }\end{array}$ & 3.39 & 1.06 & -.13 & .13 & .07 & -.08 & $-.20^{*}$ & -.08 & .06 & -.13 & $(.80)$ \\
\hline
\end{tabular}

Note. ${ }^{*} p<.05 . * * p<.01 . * * * p<.001$. Values on the diagonal in parentheses are Cronbach's alphas.

Figure 2: Mediation results of structural equation modelling

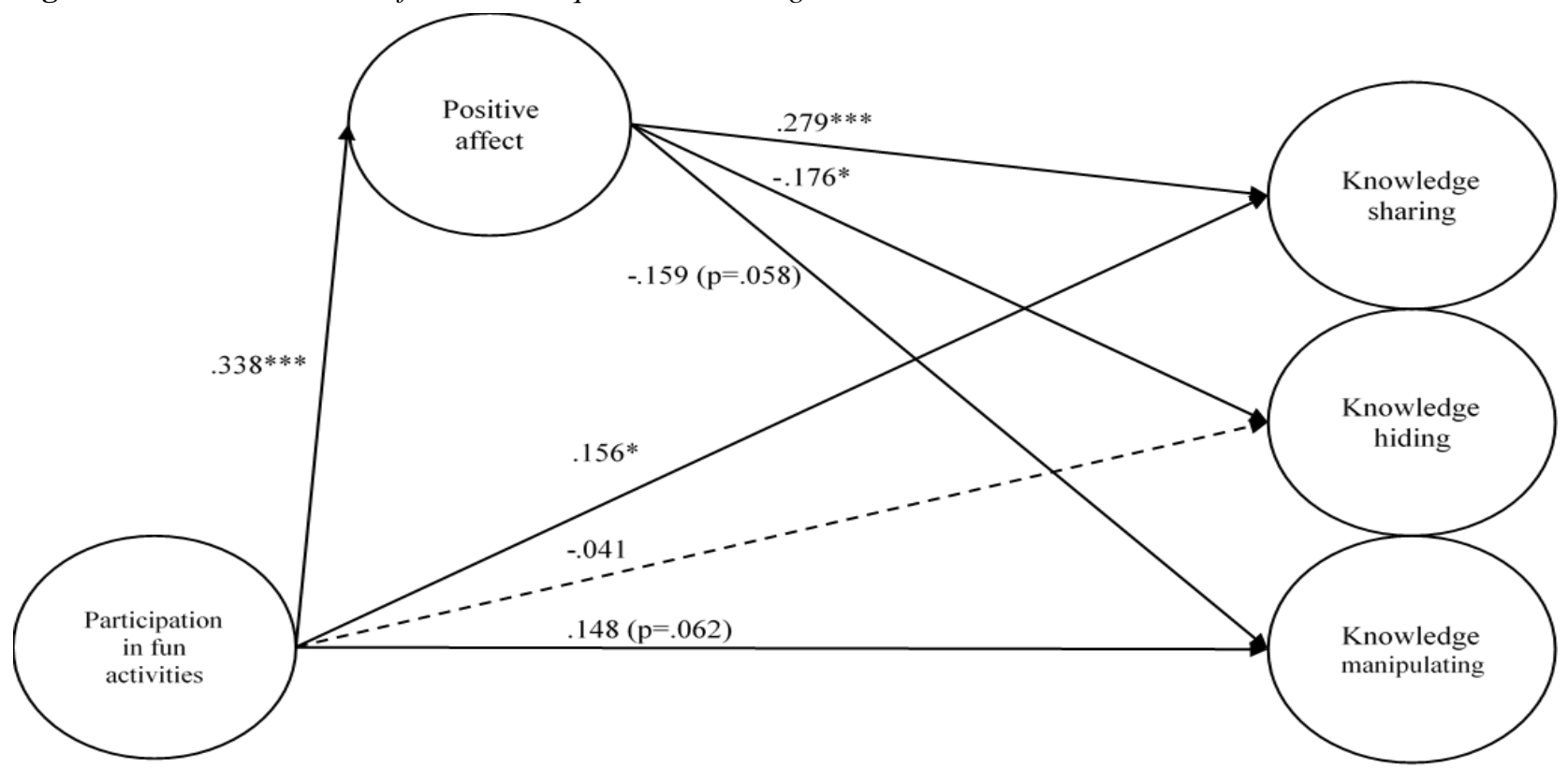

Note. Standardized regression coefficients are shown. Dashed lines indicate insignificant paths. Gender, years in organization, and years in the field included as control variables. $* p<.05$. ** $p<.01$. *** $p<.001$. Significant indirect paths: Participation in fun activities to knowledge sharing $(\beta=.180, p<.05)$, participation in fun activities to knowledge hiding $(\beta=-.103, p<.05)$, participation in fun to knowledge manipulating $(\beta=-.104, p=.067)$.

\subsection{Indirect Effects}

Indirect effects reflect the extent that an independent variable (i.e. participation in fun activities) influences the outcome variables (i.e., knowledge sharing, 
knowledge hiding, knowledge manipulating) through a mediating mechanism (i.e. positive affect). The second hypothesis posited that positive affect will mediate the relationship between participation in fun activities and the three knowledge management behaviors. The results indicate that, via positive affect, participation in fun activities has a positive indirect effect on knowledge sharing $(\beta=.180, p<.05)$ and a negative indirect effect on knowledge hiding $(\beta=-.103, p<.05)$ and knowledge manipulating $(\beta=-.104, p=.067)$. These results, combined with the direct effect results show positive affect partially mediates the relationship between participation in fun activities and both knowledge sharing and knowledge manipulating, and fully mediates the relationship between participation in fun activities and knowledge hiding.

\subsection{Moderation Effects}

Latent interaction SEM techniques were used to test the moderation hypotheses [48]. To examine the moderating role of citizenship pressure on the direct relationship between participation in fun activities and knowledge management behaviors (Hypothesis 3), we first centered our independent and moderation variables [49] and then multiplied them to develop an interaction term. Supporting Hypothesis 3, citizenship pressure moderates the relationship between participation in fun activities and knowledge manipulating $(\beta=-.151, p<$ $.05)$. A plot facilitating the interpretation of this significant moderation is shown in Figure 3.

Figure 3: Citizenship pressure as a moderator of the relationship between participation in fun activities and knowledge manipulating

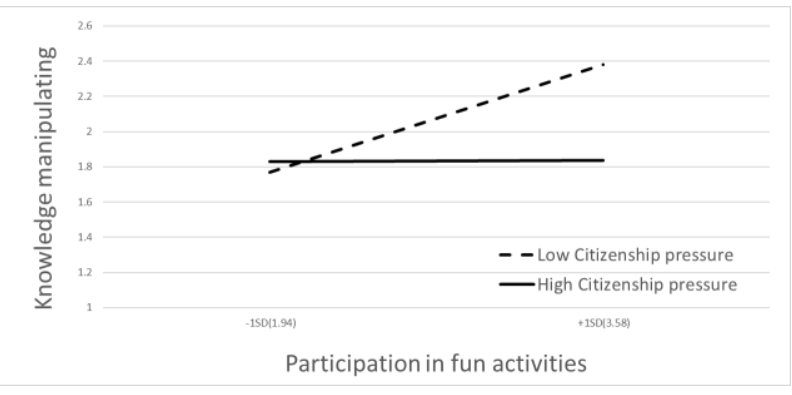

Hypothesis 4 postulated citizenship pressure moderates the relationship between participation in fun activities and positive affect and was supported by the data $(\beta=.137, p<.05)$. Figure 4 illustrates this significant moderation.

Lastly, when citizenship pressure is high, there will be a positive indirect effect of participation in fun activities on knowledge sharing (Hypothesis 5a), and a negative indirect effect of participation in fun activities on knowledge hiding (Hypothesis 5b) and knowledge manipulating (Hypothesis 5c). While Hypothesis 5 was not supported, results revealed two unexpected findings. Specifically, when citizenship pressure is low, there is a negative indirect effect of participation in fun activities on knowledge sharing $(\beta=-.041, p<.05)$, and a positive indirect effect of participation in fun activities on knowledge hiding $(\beta=.022, p=.065)$.

Figure 4: Citizenship pressure as a moderator of the relationship between employee participation in fun activities and positive affect

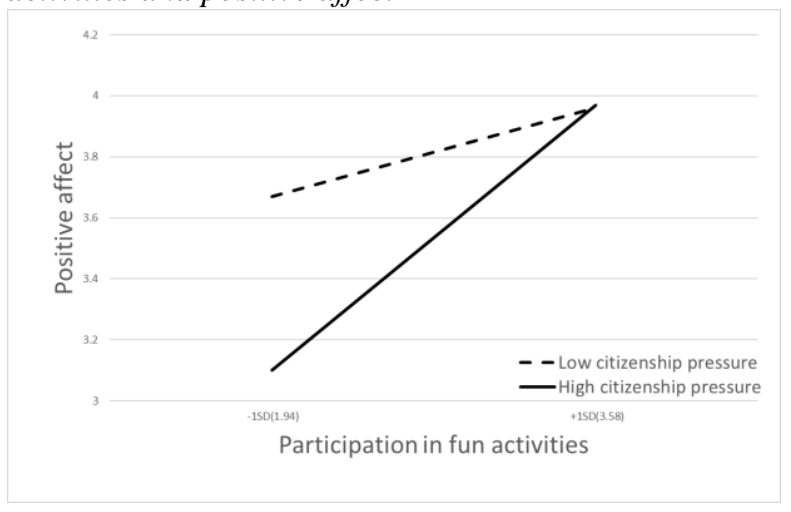

\section{Discussion}

This research explores the inherent motivational tension to share knowledge for collective interests or hide/manipulate knowledge for personal interests [11] within a workplace fun context. This research draws from a social exchange theory (SET) approach [21] to investigate how participation in fun activities influences knowledge management behaviors (KMBs), and specifically examines the role of positive affect and citizenship pressure within this relationship. As expected, the results show that the effects of participation in fun activities on KMBs is dependent on whether participation in fun activities leads to positive affect (i.e. employees enjoy participating in the fun activities). Further, the results also provide evidence that citizenship pressure may positively affect employee behavior in the form of positive knowledge exchanges. In sum, this research provides important theoretical contributions that offer unique insights to further our understanding of the effects of participation in fun activities on KMBs.

\subsection{Theoretical Implications}

This research contributes to the workplace fun literature in predominantly two ways. First, this research shows that the impact of participation in fun activities on KMBs is dependent on whether or not the 
participation in fun activities leads to positive affect. On the one hand, participation in fun activities may lead to positive knowledge exchanges (i.e., increased shared, decreased hiding, decreased manipulating) via positive affect. On the other hand, participation in fun activities may also directly lead to a negative knowledge exchange (i.e. increased manipulating). These opposing effects are consistent with the workplace fun literature showing employees' mixed views of workplace fun [9, 7], as well as extend our understanding of how participation in fun activities at work may lead to positive and negative outcomes in the form of KMBs. Most importantly, this research emphasizes the critical importance of positive affect in the relationship between participation in fun activities and KMBs.

Second, this research also highlights the role of citizenship pressure on the relationship between participation in fun activities and KMBs. In contrast to the majority of research on citizenship pressure that suggests the detrimental effects of such pressure [34, 24], this research demonstrates that citizenship pressure may also positively shape employee behavior. In particular, we find low levels of citizenship pressure can promote negative knowledge exchange (i.e. when pressure is low, participation in fun activities leads to knowledge manipulating) as well as can reduce positive knowledge exchanges (i.e. when pressure is low, participation in fun activities decreases sharing and increases hiding via positive affect).

\subsection{Practical Implications}

This research encourages managers to implement workplace fun activities within their teams and across their organization, as well as to support employees in developing and participating in fun workplace activities. This recommendation is worthy of consideration since this research shows participation in fun activities can lead to positive knowledge exchanges when participation leads to positive affect (i.e. employees enjoy participating in the fun activity). Managers must be cognizant, however, employees participating in fun activities that they do not enjoy - possible because they are pressured to do so [50] or are overwhelmed with other work demands [51] - may use their participation for self-interested reasons and perform negative knowledge exchanges (e.g. increased knowledge manipulation). Perhaps managers could foster the enjoyability of fun activities by encouraging employees to develop their own fun activities. By having the employees 'own' these activities, it may lead to greater enjoyment from the employees. Furthermore, organizations should evaluate the fun activities that they offer to determine whether employees are actually enjoying the activity. This well help ensure that organizations are investing in fun activities that will have a positive impact on employees' behavior.

This research also suggests that citizenship pressure may be one lever managers can pull on to ensure that participation in fun activities leads to positive knowledge exchanges. Consistent with the prevailing management literature [22, 23, 24], this research does not support managers exerting high levels of pressure on employees to go above and beyond. Instead, this research suggests that, just like high levels of citizenship pressure, low levels may also be detrimental for the organization [31, 47], Managers should ensure that, while there is not a high level of pressure on employees, employees experience some pressure to perform OCBs.

\subsection{Limitations and Future Research}

There are several notable limitations to this study that point to areas for future research. Empirically, the data consist of self-report and manager-reported, and thus could involve reporter bias. Future research may benefit from the inclusion of objective data (e.g. organizational records) or qualitative explorations (e.g. participant observation) of the phenomena. While this study's multi-wave design does help reduce common method bias [37], future research should utilize experimental designs to further explore the causal mechanisms linking participation in workplace fun and KMBs. As well, positive affect was measured after the participation in fun activities survey, reflecting a post-hoc appraisal of the event [7]. Future research may benefit from measuring positive affect before, during, and after engaging in the fun activity. Further, data were collected from a sample of employees in single start-up in Canada, possibly reflecting generalizability issues. Studies such as this one need to be conducted in other companies and countries to help us understand how macro-level constructs such as industry or national culture influence not only employee behavior (i.e., tendency to leverage knowledge, participate in fun activities) but also organizational outcomes.

Theoretically, we note that much of the workplace fun literature has been limited to the theorizations of affective events theory [22] and broaden-and-build theory [23]. The current study, which is grounded in social exchange theory [21], suggests that different constructs may need to be included in research studies focusing on workplace fun to help us better understand how workplace fun may positively and negatively affect the organization. Future research may benefit from the development of tools and theory that facilitate the examination of the dark side of workplace fun.

\section{References}


[1] Barley, W. C., Treem, J. W., \& Kuhn, T., "Valuing multiple trajectories of knowledge: A critical review and agenda for knowledge management research", Academy of Management Annals, 12(1), 2018, pp. 278-317.

[2] Wang, S., \& Noe, R. A., "Knowledge sharing: A review and directions for future research." Human resource management review, 20(2), 2010, pp. 115-131. [3] Stenius, M., Haukkala, A., Hankonen, N., \& Ravaja, N., "What Motivates Experts to Share? A Prospective Test of the Model of Knowledge-Sharing Motivation", Human Resource Management, 56(6), 2017, pp. 871-885.

[4] Wu, W. L., \& Lee, Y. C., "How to make a knowledge-sharing group: a group social capital perspective", Personnel Review, 45(3), 2016, pp.523538.

[5] Fluegge, E. R. "Who put the fun in functional? Fun at work and its effects on job performance", 2008, University of Florida.

[6] Thomas-Hunt, M. C., Ogden, T. Y., \& Neale, M. A., "Who's really sharing? Effects of social and expert status on knowledge exchange within groups", Management Science, 49(4), 2003pp. 464-477

[7] Michel, J. W., Tews, M. J., \& Allen, D. G., "Fun in the workplace: A review and expanded theoretical perspective", Human Resource Management Review, 29(1), 2019, pp. 98-110.

[8] Petelczyc, C. A., Capezio, A., Wang, L., Restubog, S. L. D., \& Aquino, K, "Play at work: An integrative review and agenda for future research", Journal of Management, 44(1), 2018, pp.161-190.

[9] Tews, M. J., Michel, J. W., \& Allen, D. G., "Fun and friends: The impact of workplace fun and constituent attachment on turnover in a hospitality context", Human Relations, 67(8), 2014, pp. 923-946.

[10] Von Krogh, G., "Care in knowledge creation", California management review, 40(3), 1998, pp. 133153.

[11] Rhee, Y. W., \& Choi, J. N. "Knowledge management behavior and individual creativity: Goal orientations as antecedents and in-group social status as moderating contingency", Journal of Organizational Behavior, 38(6), 2016, pp. 813-832.

[12] Kimmerle, J., Wodzicki, K., Jarodzka, H., \& Cress, U., "Value of information, behavioral guidelines, and social value orientation in an information-exchange dilemma", Group Dynamics: Theory, Research, and Practice, 15(2), 2011, pp. 173.

[13] Bolton SC, Houlihan M. "Are we having fun yet? A consideration of workplace fun and engagement" Employee Relations. 31(6), 2009, pp. 556-68.
[14] Plester, B. \& Hutchison, A. "Fun times: the relationship between fun and workplace engagement." Employee Relations, 38(3), 2016, pp. 332-350.

[15] Fleming, P., \& Sturdy, A. "“Just be yourself!" Towards neo-normative control in organisations?", Employee Relations, 31(6), 2009, pp.569-583.

[16] Redman, Tom, and BRIAN P. Mathews. "Managing services: should we be having fun?." Service Industries Journal 22(3), 2002, pp.51-62. [17] Warren, Sam, and Stephen Fineman. "Don't get me wrong, it's fun here, but...." Humour, work and organization, 2007, pp. 92-110.

[18] De Vries, R. E., Van den Hooff, B., \& de Ridder, J. A. "Explaining knowledge sharing: The role of team communication styles, job satisfaction, and performance beliefs", Communication research, 33(2), 2006, pp. 115-135.

[19] Lawler, E. J. "An affect theory of social exchange”, American Journal of Sociology, 2001. 107(2), pp. 321352.

[20] Blau, P. "Exchange and Power in Social Life.", Wiley, 1964, New York.

[21] Cropanzano, R., Anthony, E. L., Daniels, S. R., \& Hall, A. V., "Social exchange theory: A critical review with theoretical remedies", Academy of Management Annals, 11(1), 2017, pp. 479-516.

[22] Bolino, M. C., Turnley, W. H., Gilstrap, J. B., \& Suazo, M. M., "Citizenship under pressure: What's a "good soldier" to do?". Journal of Organizational Behavior, 31(6), 2010, pp. 835-855.

[23] Lin, K. J., Savani, K., \& Ilies, R. "Doing good, feeling good? The roles of helping motivation and citizenship pressure", Journal of Applied Psychology. Advance online publication. 2019.

[24] Bolino, M. C., Klotz, A. C., Turnley, W. H., \& Harvey, J., "Exploring the dark side of organizational citizenship behavior", Journal of Organizational Behavior, 34(4), 2013, pp. 542-559.

[25] Lin, K., Jia, K., \& Remus, I. "Doing good, feeling good? The roles of helping motivation and citizenship pressure." Journal of Applied Psychology, 2019.

[26] Weiss, H. M., \& Cropanzano, R., "Affective events theory: A theoretical discussion of the structure, causes and consequences of affective experiences at work." In B. M. Staw \& L. L. Cummings (Eds.), Research in organizational behavior, 18, 1996, pp. 1-74.

[27] Fredrickson, B. L., "The role of positive emotions in positive psychology: The broaden-and-build theory of positive emotions", American Psychologist, 56(3), 2001, pp. 218-226.

[28] Emerson, Richard M. "Social exchange theory." Annual review of sociology, 2:1, 1976, pp. 335-362.

[29] Staples, D.S., \& Webster, J., "Exploring the effects of trust, task interdependence and virtualness on 
knowledge sharing in teams", Information Systems Journal, 18(6), 2008, pp. 617-640

[30] Serenko, A. \& Bontis, N., "Negotiate, reciprocate, or cooperate? The impact of exchange modes on interemployee knowledge sharing", Journal of Knowledge Management, 20(4), 2016, pp. 687-712.

[31] Renzl, Birgit., "Trust in management and knowledge sharing: The mediating effects of fear and knowledge documentation", The International Journal of Management Science, 36 (2), 2008, pp. 206-220.

[32] Cabrera, A., \& Cabrera, E. F., "Knowledge-sharing dilemmas. Organization Studies", 23(5), 2002, pp. 687710.

[33] Connelly, C. E., Zweig, D., Webster, J., \& Trougakos, J. P., Knowledge hiding in organizations. Journal of Organizational Behavior, 33(1), 2012, pp. 6488.

[34] Clouse, R.W. and Spurgeon, K.L., "Corporate analysis of humor", Psychology: A Journal of Human Behavior, 32:3, 1995, pp. 1-24

[35] Verykios, V. S., \& Gkoulalas-Divanis, A., "A survey of association rule hiding methods for privacy". In Privacy-Preserving Data Mining (pp. 267-289). Springer, Boston, MA. 2008.

[36] MacKenzie, S., Podsakoff, P., \& Podsakoff, N.

"Construct measurement and validation procedures in

MIS and behavioral research: Integrating new and existing techniques." MIS quarterly 35(2), 2011, pp. 293-334.

[37] Podsakoff, P., MacKenzie, S., \& Podsakoff, N. "Sources of method bias in social science research and recommendations on how to control it." Annual review of psychology, 63, 2012, pp. 539-569.

[38] Collins, C. \& Smith, K. "Knowledge exchange and combination: The role of human resource practices in the performance of high-technology firms." Academy of management journal, 49(3), 2006, pp. 544-560.

[39] Watson, D., Clark, L. A., \& Tellegen, A. "Development and validation of brief measures of positive and negative affect: the PANAS scales", Journal of personality and social psychology, 54(6), 1988, pp. 1063.

[40] Bolino, M. C., Hsiung, H.-H., Harvey, J., \& LePine, J. A. "“Well, I'm tired of tryin'!" Organizational citizenship behavior and citizenship fatigue", Journal of Applied Psychology, 100(1), 2015, pp. 56-74.

[41] Bratton, V.K., Dodd, N.G. and Brown, F.W., 2011. The impact of emotional intelligence on accuracy of self-awareness and leadership performance. Leadership \& Organization Development Journal, 32(2), pp.127149.

[42] Karl, K., Peluchette, J., Hall, L. \& Harland, L. "Attitudes toward workplace fun: A three sector comparison." Journal of Leadership \& Organizational Studies, 12: 2, 2005, pp. 1-17.

[43] Browne, M. W., \& Cudeck, R. "Alternative ways of assessing model fit." Sage focus editions, 154, 1993, pp. 136-136.

[44] Tabachnick, B., Fidell, L., \& Ullman, J. Using multivariate statistics. Vol. 5. Boston, MA: Pearson, 2007.

[45] Steiger, J. H. "Understanding the limitations of global fit assessment in structural equation modeling." Personality and Individual differences, 42,5, 2007, pp. 893-898.

[46] Hu, L. \& Bentler, P., "Cutoff criteria for fit indexes in covariance structure analysis: Conventional criteria versus new alternatives." Structural equation modeling: a multidisciplinary journal, 6:1, 1999, pp. 1-55.

[47] Shrout, P. E., \& Bolger, N., "Mediation in experimental and nonexperimental studies: new procedures and recommendations." Psychological methods, 7: 4, 2002, pp. 422.

[48] Steinmetz, H., Davidov, E., \& Schmidt, P., "Three approaches to estimate latent interaction effects: Intention and perceived behavioral control in the theory of planned behavior", Methodological Innovations, 6(1), 2011, pp. 95-11

[49] Bottomley, Paul, Ahmed Mohammed Sayed Mostafa, Julian Seymour Gould-Williams, and Filadelfo León-Cázares. "The impact of transformational leadership on organizational citizenship behaviours: The contingent role of public service motivation.", British Journal of Management, 27:2, 2016, pp. 390-405.

[50] Fleming, P., \& Sturdy, A. "“Just be yourself!" Towards neo-normative control in organisations?" Employee Relations, 31: 6, 2009, pp. 569-583.

[51] R. Baptiste, N. "Fun and well-being: insights from senior managers in a local authority." Employee Relations, 31: 6, 2009. pp. 600-612. 